\title{
Predictive value of preprocedural albuminuria for contrast-induced nephropathy non-recovery in patients undergoing percutaneous coronary intervention
}

\author{
Hanchuan Chen ${ }^{1} \cdot$ Zhebin You $^{2}$. Sicheng Zhang ${ }^{1} \cdot$ Chen He$^{1} \cdot$ Haoming He ${ }^{1} \cdot$ Manjing Luo ${ }^{1} \cdot$ Xueqin Lin ${ }^{1}$. \\ Liwei Zhang ${ }^{1} \cdot$ Kaiyang Lin ${ }^{1} \cdot$ Yansong Guo ${ }^{1}$ (D)
}

Received: 29 September 2020 / Accepted: 13 February 2021 / Published online: 6 March 2021

(c) The Author(s) 2021

\begin{abstract}
Objective The present study investigated the predictive value of albuminuria for contrast-induced nephropathy (CIN) nonrecovery in patients undergoing percutaneous coronary intervention (PCI).

Methods We retrospectively enrolled 550 consecutive patients inflicted with CIN after PCI and reassessing kidney function among 1 week-12 months between January 2012 and December 2018. Patients were stratified into three groups according to urine albumin: negative group (urine dipstick negative), trace group (urine dipstick trace) and positive group (urine dipstick $\geq 1+$ ). The primary outcomes were CIN non-recovery (a decrease of serum creatinine which remains $\geq 25 \%$ or $0.5 \mathrm{mg}$ / $\mathrm{dL}$ over baseline at 1 week-12 months after PCI in patients inflicted with CIN). The odds ratio (OR) of CIN non-recovery was analyzed by logistic regression using the negative urine dipstick group as the reference group.

Results Overall, 88 (16.0\%) patients had trace urinary albumin, 74 (13.5\%) patients had positive urinary albumin and 40 (7.3\%) patients developed CIN non-recovery. Patients with positive urinary albumin had significantly higher incidence of CIN non-recovery [negative (3.4\%), trace (11.4\%) and positive (23.0\%), respectively; $P<0.0001$ ]. Multivariate analysis showed that trace and positive urinary albumin were associated with an increased risk of CIN non-recovery (trace vs negative: OR 2.88, $P=0.022$; positive vs negative: OR 2.99, $P=0.021$ ). These associations were consistent in subgroups of patients stratified by CIN non-recovery risk predictors. And CIN non-recovery was associated with an increased risk of long-term mortality during a mean follow-up period of 703 days $(P<0.001)$.
\end{abstract}

Conclusion Preprocedural albuminuria was associated with CIN non-recovery in patients undergoing PCI.

Keywords Albuminuria $\cdot$ Contrast-induced nephropathy $\cdot$ Recovery $\cdot$ Percutaneous coronary intervention

Hanchuan Chen and Zhebin You contributed equally to this work.

\author{
Kaiyang Lin \\ lky7411@sina.com \\ Yansong Guo \\ ysguo1234@126.com
}

1 Department of Cardiology, Fujian Provincial Key Laboratory

of Cardiovascular Disease, Fujian Provincial Hospital,

Shengli Clinical Medical College of Fujian Medical

University, Fuzhou 350001, China

2 Department of Geriatric Medicine, Fujian Key Laboratory of Geriatrics, Fujian Provincial Center for Geriatrics, Fujian Provincial Hospital, Fujian Medical University, Fuzhou 350001, China

\author{
Abbreviations \\ CIN Contrast-induced nephropathy \\ PCI Percutaneous coronary intervention \\ $\mathrm{SCr} \quad$ Serum creatinine \\ BUN Blood urea nitrogen \\ IABP Intra-aortic balloon pump \\ LDL-C Low-density lipoprotein cholesterol \\ LVEF Left ventricular ejection fraction \\ eGFR Estimated glomerular filtration rate
}

\section{Introduction}

Contrast-induced nephropathy (CIN), a common complication after coronary intervention procedure, has proved to be associated with poor short- and long-term outcomes [1]. However, the value of CIN is under heated debate [2,3]. On 
one hand, most of it was temporary strike meaning limited effects on prognosis. On the other hand, it also confused the transient with persistent renal damage which makes the patients in mortal danger less distinguishable. Only when physicians identify the true high-risk patients who are susceptible to poor outcomes, they could take timely, economical and effective measures. The prognosis is not only determined on the severity of CIN but also the progression of renal recovery which was highlighted by several studies that indicated a very close association with the major adverse cardiovascular and nephropathic events. Therefore, we should remain vigilant at the renal function for a long postoperative period, identify the high-risk patients who are likely to develop CIN non-recovery and take necessary measures in time.

It is well established that albuminuria is useful in reflecting the development and mortality of the acute phase of kidney injury [4]. Moreover, it is also commonly accepted in the chronic phase of renal damage in the definition, staging, and prediction for outcome of chronic kidney disease (CKD) [5]. However, the association between albuminuria and CIN non-recovery remains unknown. Therefore, we sought to determine the predictive value of albuminuria for CIN non-recovery in patients undergoing percutaneous coronary intervention (PCI).

\section{Methods}

\section{Study population}

This is a retrospective observational study conducted at Fujian provincial hospital. Between January 2012 and December 2018, a total of 646 consecutive patients inflicted with CIN after PCI and reassessing kidney function among 1 week-12 months were enrolled. Exclusion criteria were as follows: (1) end-stage renal disease (eGFR $<15 \mathrm{~mL} /$ $\left.\mathrm{min} / 1.73 \mathrm{~m}^{2}\right)$ or long-term dialysis treatment $(n=10)$; (2) patients who died within 1 week after PCI $(n=25)$; (3) lack of data on $\mathrm{SCr}(n=40)$; (4) cancer with expectation of life less than 1 year $(n=8)$; (5) use of contrast medium within the last 7 days $(n=7)$; (6) nonsteroidal anti-inflammatory drugs (NSAIDs) or other nephrotoxic drugs use within $48 \mathrm{~h}$ before the procedure $(n=6)$. (7) Patients who received IABP treatment $(n=0)$. Consequently, 550 patients were enrolled in this study.

\section{Definitions}

CIN was defined as an absolute SCr increase $0.5 \mathrm{mg} / \mathrm{dL}$ or a relative increase in $\mathrm{SCr} \geq 25 \%$ within $48 \mathrm{~h}$ after contrast medium exposure [6]. CIN non-recovery was defined as a relative decrease of serum creatinine which remains $\geq 25 \%$ or $0.5 \mathrm{mg} / \mathrm{dL}$ over baseline at 1 week-12 months after PCI in patients who developed CIN. Albuminuria was measured using a dipstick before procedure, we defined as follow: urine dipstick negative as "negative albuminuria", urine dipstick trace as "trace albuminuria" and urine dipstick $\geq 1+$ as "positive albuminuria" [7].

Hypotension was defined as systolic blood pressure $(\mathrm{SBP})<80 \mathrm{mmHg}$ for at least $1 \mathrm{~h}$ requiring the support with medications or intra-aortic balloon pump (IABP) within $24 \mathrm{~h}$ peri-procedure [8].

The primary end point was the occurrence of CIN nonrecovery. Additional end point was long-term mortality.

\section{Study protocol}

$\mathrm{SCr}$ concentrations were measured on hospital admission before the procedure, every day for the following 2 days, at discharge, 1 week-12 months after discharge. Modified diet in renal disease (MDRD) formula was used to eGFR [9]. Routine urinalysis of fresh urine samples in morning which involved urinary albumin was measured before procedure and tested using an Urisys automatic analyzer. The $0.9 \%$ normal saline at a rate of $1 \mathrm{~mL} / \mathrm{kg} / \mathrm{h}$ was administered intravenously for approximately $12 \mathrm{~h}$ during the perioperative period $(0.5 \mathrm{~mL} / \mathrm{kg} / \mathrm{h}$ if patients with heart failure). Relevant baseline, clinical data, and laboratory were recorded during the hospital. After discharge, all patients were measured routine urinalysis 1 week-12 months after discharge and subjected to follow-up for more than 1 year, which were monitored and recorded by nurses using clinical visits or telephone contact. This study was approved by the ethic committee of our institution and the subjects gave informed consent.

\section{Percutaneous coronary intervention}

PCI was performed using standard techniques including standard guide catheters, guidewires, balloon catheters, and stents via the femoral or radial approach according to current guidelines [10]. The non-ionic, low-osmolar contrast media (either Iopamiron or Ultravist, both $370 \mathrm{mg} \mathrm{I} / \mathrm{mL}$ ) was used in all patients. The contrast dose, pharmacological therapies, IABP support were left to the discretion of cardiologists and patients' condition.

\section{Statistical analysis}

Statistical analysis was done with $\mathrm{R}$ version 4.0.2. Patients were stratified into three groups according to urinary albumin: negative group (urine dipstick negative), trace group (urine dipstick trace) and positive group (urine dipstick $\geq 1+$ ). Normally distributed continuous variables are reported as mean \pm standard deviation (SD). Categorical 
data are expressed as absolute value and percentage. The Student's $t$ test, Wilcoxon rank sum test, or one-way analysis of variance was performed to determine the differences among groups. Categorical variables were compared by Chisquare test or Fisher exact test. Risk factors were identified on univariate logistic regression analysis included variables with $P$ value $<0.05$. Multivariable-logistic analysis was used to examine the association of positive group (urine dipstick $\geq 1+$ ) and trace group (urine dipstick trace) (vs negative group) with CIN non-recovery in models adjusted as follows: model 1 adjusted for age, eGFR $<90 \mathrm{~mL} / \mathrm{min} / 1.73 \mathrm{~m}^{2}$, and model 2 adjusted for variables in model 1 plus diabetes mellitus, left ventricular ejection fraction (LVEF), anemia. Kaplan-Meier curve was used to compute the cumulative incidence of mortality stratified by urinary albumin levels and was compared using the log-rank test. A 2 -sided $P$ value $<0.05$ was considered statistically significant.

\section{Results}

\section{Baseline characteristics}

A total of 550 consecutive patients were included. 161 $(29.3 \%)$ were female, and the overall patient age was $65.3 \pm 11.4$ years. Baseline patient eGFR and $\mathrm{SCr}$ were $105 \pm 31.2 \mathrm{~mL} / \mathrm{min} / 1.73 \mathrm{~m}^{2}$ and $0.85 \pm 0.67 \mathrm{mg} / \mathrm{dL}$. Overall, 40 (7.3\%) patients developed CIN non-recovery.

Table 1 shows the baseline characteristics of patients with and without CIN non-recovery. Patients with CIN nonrecovery were older, more frequently to have anemia, diabetes, worse renal function, higher baseline of NT-proBNP, urine albumin levels, and lower LVEF.

\section{CIN non-recovery incidences and risk factors}

The incidences of CIN non-recovery were $3.40,11.40$, and $23.00 \%$ in patients in negative group, trace group and positive group (Fig. 1). Univariate logistic regression analysis indicated that age, eGFR $<90 \mathrm{~mL} / \mathrm{min} / 1.73 \mathrm{~m}^{2}$, diabetes mellitus, LVEF and anemia were significantly associated with CIN non-recovery (all $P<0.05$ ). In multivariableadjusted logistic proportional hazard models, compared with negative group, trace group and positive group were both significantly associated with increased risk of CIN non-recovery, independent of demographics and clinical risk factors (Table 2). In model 1, after adjustment for age and eGFR $<90 \mathrm{~mL} / \mathrm{min} / 1.73 \mathrm{~m}^{2}$, trace urinary albumin and positive urinary albumin were both significantly correlated with CIN non-recovery, and the odds ratios (OR) values were 3.44 (95\% CI 1.38-8.33) and 5.66 (95\% CI 2.49-13.06), respectively. In model 2, after adjusting for model 1 plus diabetes mellitus, LVEF, anemia, trace urinary albumin and positive urinary albumin remained associated with increased risk of CIN non-recovery, the OR values were 2.88 (95\% CI $1.14-7.11, P=0.022)$ and 2.99 (95\% CI $1.17-7.56$, $P=0.021)$, respectively.

\section{Subgroup analysis based on CIN non-recovery risk predictors}

Figure 2 shows subgroup analysis stratified by CIN nonrecovery risk factors, the association between urinary albumin levels and CIN non-recovery were consistent among these subgroups, there was no effect modification of anemia, diabetes and eGFR.

\section{Follow-up}

Median follow-up was 703 days (422-1060 days). Clinical outcomes were available for 531 patients (96.5\%). 36 patients died, which represents $6.78 \%$ of all patients enrolled in our study. Kaplan-Meier curve demonstrated that patients suffering from $\mathrm{CIN}$ non-recovery presented high all-cause mortality $(P<0.001)$ (Fig. 3).

\section{Discussion}

To our knowledge, this is the first study to demonstrate that preprocedural albuminuria was associated with CIN non-recovery in patients undergoing PCI. It showed that trace and positive urinary albumin were associated with an increased risk of CIN non-recovery (trace vs negative: OR $2.879, P=0.022$; positive vs negative: $\mathrm{OR} 2.991, P=0.021$ ) which was consistent among several subgroups of patients stratified by CIN non-recovery risk predictors. Furthermore, the occurrence of CIN non-recovery was associated with higher mortality $(P<0.001)$.

CIN, generally considered to rank the third among the causes of hospital-acquired kidney injury [11], could raise in-hospital mortality rate by about fivefolds and 1- and 5 -year mortality rate about fourfolds [1]. It is contrary to the stereotype that CIN is always reversible and returns to baseline quickly, persistent renal damage occurred in 16.4-45.9\% patients with CIN [12-14] and significantly increased the risk of adverse cardiovascular events and renal outcome compared with both patients with transient renal damage $(P=0.015)$ and without acute kidney injury $(P=0.0001)$ after coronary angiography [12]. Therefore, it is important to identify the high-risk patients with CIN developing into non-recovery and organize follow-ups so as to make more targeted preventive measures.

Multiple risk factors for CIN have been studied, from biomarker including NGAL, KIM-1, NAG to various clinical models such as Merhan risk score, Marenzi's simple 
Table 1 Baseline variables between CIN recovery group and non-recovery group

\begin{tabular}{|c|c|c|c|}
\hline & CIN recovery $(n=510)$ & $\begin{array}{l}\text { CIN non-recovery } \\
(n=40)\end{array}$ & $P$ value \\
\hline \multicolumn{4}{|l|}{ Demographics } \\
\hline Age, years & $64.9 \pm 11.3$ & $70.2 \pm 11.3$ & 0.006 \\
\hline Age $>75$ years, $n(\%)$ & $113(22.2 \%)$ & $14(35.0 \%)$ & 0.097 \\
\hline Sex, female, $n(\%)$ & $146(28.6 \%)$ & $15(37.5 \%)$ & 0.314 \\
\hline Systolic blood pressure, $\mathrm{mmHg}$ & $135.2 \pm 22.6$ & $130.4 \pm 29.5$ & 0.328 \\
\hline Diastolic blood pressure, $\mathrm{mmHg}$ & $76.7 \pm 14.0$ & $74.9 \pm 15.0$ & 0.474 \\
\hline \multicolumn{4}{|l|}{ Medical history } \\
\hline Hypertension, $n(\%)$ & $357(70.0)$ & $33(82.5)$ & 0.135 \\
\hline Diabetes, $n(\%)$ & 207 (40.6) & $26(65.0)$ & 0.004 \\
\hline Atrial fibrillation, $n(\%)$ & $50(9.8)$ & $7(17.5)$ & 0.170 \\
\hline Malignancy & $6(1.2)$ & $2(5.0)$ & 0.109 \\
\hline \multicolumn{4}{|l|}{ Medical therapy during hospitalization } \\
\hline Statin use, $n(\%)$ & $509(99.8)$ & $40(100)$ & 1.000 \\
\hline CCB use, $n(\%)$ & $160(31.4)$ & $13(32.5)$ & 1.000 \\
\hline Antiplatelet agents use, $n(\%)$ & $505(99.0)$ & $38(95.0)$ & 0.086 \\
\hline$\beta$-blocker use, $n(\%)$ & $412(80.8)$ & $35(87.5)$ & 0.402 \\
\hline \multicolumn{4}{|l|}{ Laboratory measurements } \\
\hline $\mathrm{WBC}, 10^{9} / \mathrm{L}$ & $8.7 \pm 3.6$ & $9.4 \pm 3.0$ & 0.193 \\
\hline Anemia, $n(\%)$ & $124(24.3 \%)$ & $19(47.5 \%)$ & 0.002 \\
\hline PLT, $10^{12} / \mathrm{L}$ & $222.8 \pm 66.5$ & $223.9 \pm 66.5$ & 0.926 \\
\hline Cholesterol, $\mathrm{mmol} / \mathrm{L}$ & $4.46 \pm 1.24$ & $4.53 \pm 1.45$ & 0.795 \\
\hline LDL-C, mmol/L & $2.92 \pm 1.10$ & $2.91 \pm 1.23$ & 0.955 \\
\hline HDL-C, mmol/L & $1.08 \pm 0.29$ & $1.11 \pm 0.32$ & 0.547 \\
\hline Urine albumin levels, $n(\%)$ & & & $<0.001$ \\
\hline Negative & $373(73.5)$ & $13(32.5)$ & \\
\hline Trace & $78(15.3)$ & $10(25.0)$ & \\
\hline Positive & $57(11.2)$ & $17(42.5)$ & \\
\hline Serum creatinine, mg/Dl & $0.8 \pm 0.5$ & $1.5 \pm 1.6$ & 0.005 \\
\hline $\mathrm{eGFR}, \mathrm{mL} / \mathrm{min} / 1.73 \mathrm{~m}^{2}$ & $107.6 \pm 28.7$ & $72.8 \pm 42.2$ & $<0.001$ \\
\hline $\mathrm{eGFR}<90 \mathrm{~mL} / \mathrm{min} / 1.73 \mathrm{~m}^{2}, n(\%)$ & $118(23.1)$ & $27(67.5)$ & $<0.001$ \\
\hline LVEF, \% & $56.2 \pm 7.9$ & $51.1 \pm 8.7$ & 0.002 \\
\hline Contrast volume, $\mathrm{mL}$ & $191.8 \pm 61.6$ & $186.2 \pm 61.9$ & 0.587 \\
\hline Number of lesions, $n$ & $2.3 \pm 0.8$ & $2.6 \pm 0.7$ & 0.015 \\
\hline Number of stents, $n$ & $1.5 \pm 0.8$ & $1.7 \pm 1.1$ & 0.452 \\
\hline
\end{tabular}

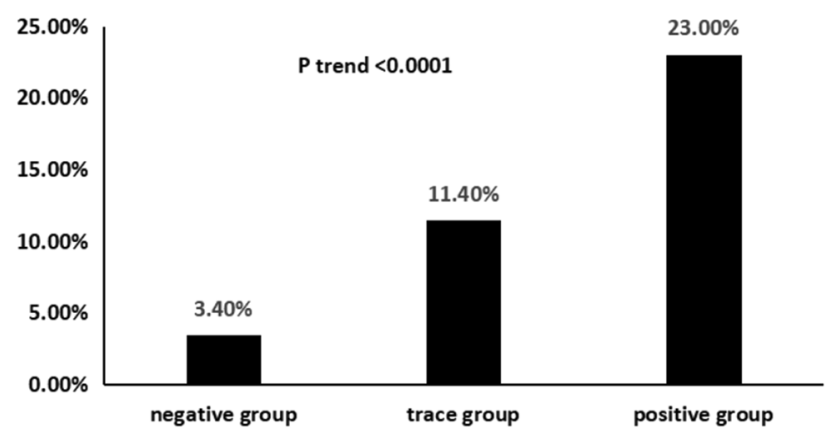

Fig. 1 Incidence of CIN non-recovery risk score, Mosquera's 5 factor score etc. containing age, comorbidities, baseline renal function, hydration usage, contrast volume and so on $[8,15,16]$. The predictive value of CIN on long-term mortality is under heated debate. On the one hand, some studies doubted the role of CM in causing CIN, as they believed the latter may be overestimated for what is actually normal fluctuation of serum creatinine in hospital [17]. On the other hand, several researchers worried the confusion of transient kidney damage with long-term renal injury will mislead physicians in terms of real perniciousness of CIN who would underestimate the risk of CIN on prognosis. Unfortunately, only a few studies further drew a distinction between the two different patterns and evaluated classical injury markers 
Table 2 Associations between urinary albumin levels and CIN non-recovery

\begin{tabular}{lclclccc}
\hline Urinary albumin & Participants, $n$ & Events, $n$ & Rate, $\%$ & Model 1* OR (95\% CI) & $P$ value & Model 2 ${ }^{\dagger}$ OR (95\% CI) & $P$ value \\
\hline Negative & 388 & 13 & 3.40 & $1.00($ ref $)$ & $1.00($ ref $)$ & \\
Trace & 88 & 10 & 11.40 & $3.44(1.38-8.33)$ & 0.006 & $2.88(1.14-7.11)$ \\
Positive & 74 & 17 & 23.00 & $5.66(2.49-13.06)$ & $<0.0001$ & $2.99(1.17-7.56)$ & 0.022 \\
\hline
\end{tabular}

$C I$ confidence interval, $H R$ hazard ratio

* Model 1 adjusted for age, eGFR $<90 \mathrm{~mL} / \mathrm{min} / 1.73 \mathrm{~m}^{2}$; ${ }^{\dagger}$ model 2 adjusted for variables in model 1 plus diabetes mellitus, LVEF, anemia

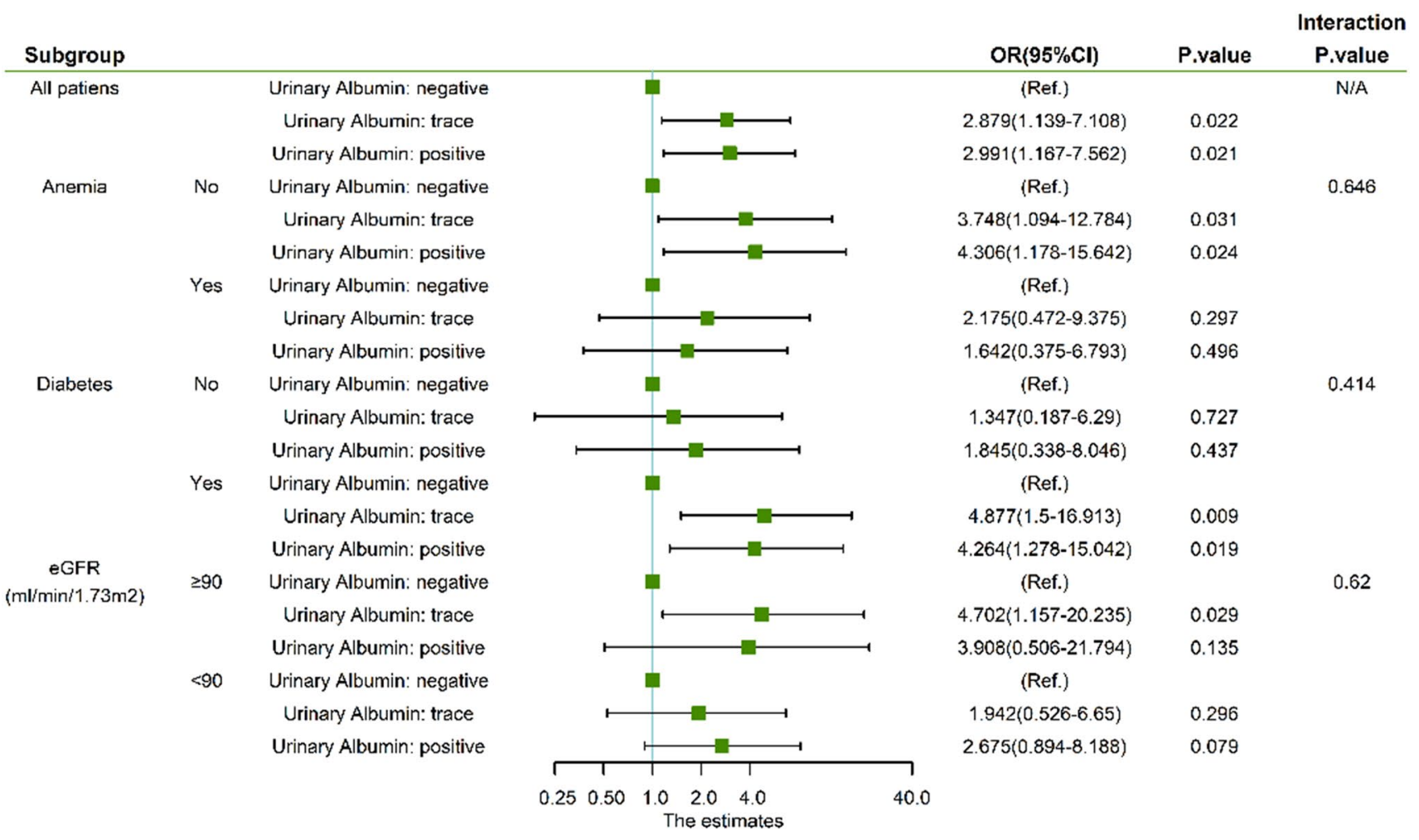

Fig. 2 Forest and interaction

for the purpose of predicting maladaptiveness or even the failure to recover.

Albuminuria is commonly accepted as an essential detection for the diagnostic, pathogenic, progression to ESRD and prognostic recommended by KDIGO guideline about CKD management [5]. Moreover, albuminuria was found to be an important risk factor for the development of AKI in patients after cardiac surgery. Molnar et al. demonstrated that individuals with the higher levels of perioperative dipstick albuminuria had the greatest risk for AKI (RR 2.46; 95\% CI 1.16-4.97) and improved the clinical prediction of AKI above clinical models alone [18]. Recently, some researchers reported a close look at the predictive value of albuminuria for CIN after coronary angiography, the study of Meng et al. and Saito et al. suggested the preprocedural albuminuria was associated with greater risk for CIN regardless of the baseline renal function $\left(\mathrm{eGFR}<30 \mathrm{~mL} / \mathrm{min} / 1.73 \mathrm{~m}^{2}\right.$ : OR $17.4, P=0.0001$; eGFR $30-44 \mathrm{~mL} / \mathrm{min} / 1.73 \mathrm{~m}^{2}$ : OR $12.1 ; P=0.0006 ;$ eGFR $\geq 60 \mathrm{~mL} / \mathrm{min} / 1.73 \mathrm{~m}^{2}: 12.1 \mathrm{vs} 5.0 \%$, $P=0.005)[19,20]$. For patients with T2DM undergoing elective cardiac catheterization, Yang et al. found preprocedural albuminuria was an independent risk factor of CIN (OR 3.8; 95\% CI 1.5-9.2; $P=0.004$ ) [7]. Their studies, however, did not attempt to assess the association of albuminuria and the long-term prognosis, let alone the repair process, also known as CIN non-recovery. To the best of our knowledge, there was not even a study focusing on the predictive value of albuminuria levels for CIN non-recovery. Our research filled the gap and provided that urine albumin level was a strong and independent predictor of CIN non-recovery after PCI even after adjusting for potential confounding factors. Meanwhile, the occurrence of CIN non-recovery was 
Fig. 3 Mortality between CIN non-recovery

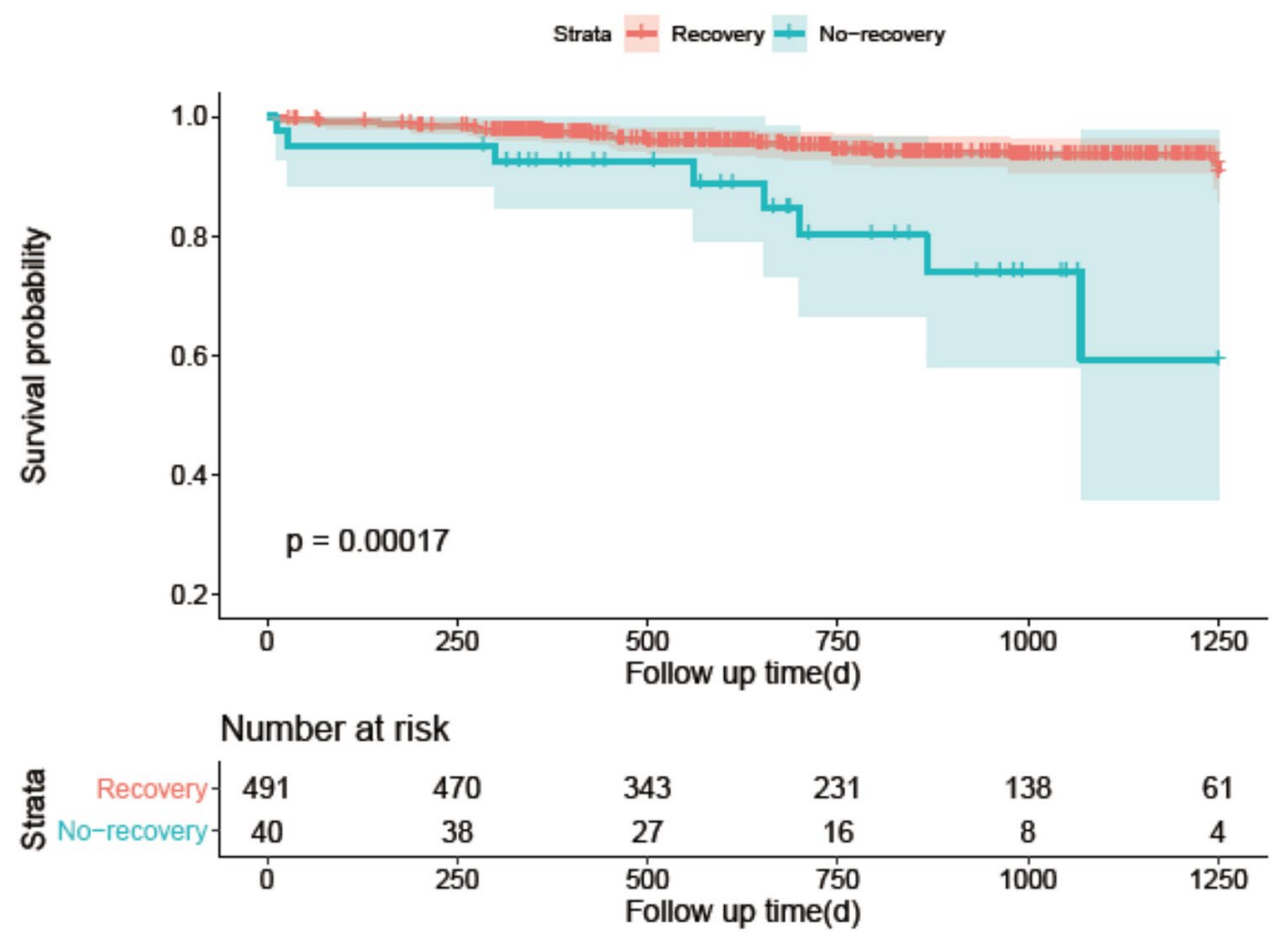

associated with higher mortality. In our study, the positive predictive value of albuminuria to CIN non-recovery was low (17\%), but its negative predictive value was $96.6 \%$, which also has important clinical significance. Use of tests with high negative predictive value (NPV) will reduce unnecessary interventions and hospitalization of patients. Furthermore, such a tests with high NPV provide necessary evidence to physicians, so that they can perform exams requiring contrast media more confidently.

The mechanisms underlying the association of albuminuria and CIN non-recovery remain uncertain. Potential pathophysiological assumptions as follows may help to understand the underlying relationship between urine albumin levels and maladaptive recovery after CIN. First, albuminuria, reflecting the overexcretion of albumin from the glomerulus or overreabsorption of albumin in proximal tubular cells proved to be a marker of wounded kidney tissue including glomerular and tubular damage after chronic, sustained or acute injury $[21,22]$ resulting in the compromise of ability to tolerate hemodynamic changes and other nephrotoxic insults and was associated with the long-term adverse cardiovascular and renal outcomes [23]. Second, a high concentration of albumin in tubular itself may aggravate the damage after administration of CM leading to higher osmotic pressure, severer renal medullary hypoxia and renal fibrosis even worse which was common pathological manifestation of CKD [24]. Finally, in early non-recovery stage of CIN, or initial stage of CKD injury in other words, interstitial capillaries become increasingly permeable allowing that many plasma proteins that never reach the renal interstitium are able to do so and trigger an inflammatory response [25] via the upregulation of $\mathrm{NF}-\kappa \mathrm{B}$ or $\mathrm{MCP}-1$ [26] and activate oxygen species (ROS) formation [27] leading to glomerulosclerosis.

\section{Limitations}

Our study has several limitations. First, this study was observational from a single center with limited samples which may be affected by confounding and selection biases, calling for multiple centers and sufficient quantity of samples in the future. Second, the urine albumin levels were measured using semiquantitative methods which were not accurate as quantitative methods. Third, considering the potential effects of two continuous stages of CIN recovery process may be a mixed factor, the definition of CIN non-recovery may not be accurate, but it also provides an essential detection in the follow-up period. Fourth, data of more detailed follow-up information about cardiovascular and renal outcomes were not recorded. Finally, we did not confirm our conclusion through biomarkers involved in fibrosis, inflammation, oxidative stress which will be left to the next stage of series of our researches.

\section{Conclusions}

Preprocedural albuminuria was an independent risk factor for CIN non-recovery in patients undergoing PCI. As albuminuria is a convenient, rapid, cheap laboratory test that can be performed before PCI, it could help clinicians to identify 
the high-risk patients, take necessary measures and organize the follow-ups.

\section{Acknowledgements Not applicable.}

Author contributions $\mathrm{HCC}$ and ZBY contributed equally to this work and acquired the data, drafted and revised the manuscript. SCZ, CH, $\mathrm{HMH}$, and MJL assisted to acquire and interpret the data. KYL and YSG designed the study, provided supervision, and critically revised the manuscript. All authors approve the final version of the manuscript and agree to be accountable for all aspects of the study.

Funding This study was funded by a grant from the Joint Funds for the innovation of science and Technology, Fujian province (Grant Number: 2018Y9097), high-level hospital foster grants from Fujian Provincial Hospital, Fujian province, China (Grant Number: 2020HSJJ05), Fujian provincial health technology project (Grant Number: 2019-ZQN-10), National Natural Science Foundation of China General Program (Grant Number: 81873495), Natural Science Foundation of Fujian Province (Grant Number: 2018J01242), and Fujian Provincial Health Commission Youth Key Talents Project (Key Category, Grant Number: 2014-ZQN-ZD-2).

Data availability The datasets used and/or analysed during the current study are available from the corresponding author on reasonable request.

\section{Compliance with ethical standards}

Competing interests The authors declare that they have no competing interests.

Ethics approval and consent to participate The protocol fulfilled the requirements of the Declaration of Helsinki and was approved by the ethics committee of the Fujian Provincial Hospital, China (Ethics Approval Number: K2012-001-01).

Consent for publication Not applicable.

Open Access This article is licensed under a Creative Commons Attribution 4.0 International License, which permits use, sharing, adaptation, distribution and reproduction in any medium or format, as long as you give appropriate credit to the original author(s) and the source, provide a link to the Creative Commons licence, and indicate if changes were made. The images or other third party material in this article are included in the article's Creative Commons licence, unless indicated otherwise in a credit line to the material. If material is not included in the article's Creative Commons licence and your intended use is not permitted by statutory regulation or exceeds the permitted use, you will need to obtain permission directly from the copyright holder. To view a copy of this licence, visit http://creativecommons.org/licenses/by/4.0/.

\section{References}

1. Seeliger E, Sendeski M, Rihal CS, Persson PB (2012) Contrastinduced kidney injury: mechanisms, risk factors, and prevention. Eur Heart J 33(16):2007-2015. https://doi.org/10.1093/eurheartj/ ehr494

2. Diebold M, Kistler AD (2018) [Radiocontrast agents: wrongfully accused?]. Ther Umsch 75(6):359-364. https://doi. org/10.1024/0040-5930/a001009
3. Arayan A, Nigogosyan MA, Van Every MJ (2015) A retrospective review of contrast nephropathy in a general population. WMJ 114(3):95-99

4. Huang TM, Wu VC, Young GH, Lin YF, Shiao CC, Wu PC, Li WY, Yu HY, Hu FC, Lin JW, Chen YS, Lin YH, Wang SS, Hsu RB, Chang FC, Chou NK, Chu TS, Yeh YC, Tsai PR, Huang JW, Lin SL, Chen YM, Ko WJ, Wu KD (2011) Preoperative proteinuria predicts adverse renal outcomes after coronary artery bypass grafting. J Am Soc Nephrol 22(1):156-163. https://doi. org/10.1681/ASN.2010050553

5. Levin A, Stevens PE, Bilous RW, Coresh J, Francisco A, Jong PE, Griffith KE, Hemmelgarn BR, Iseki K, Lamb E, Levey AS, Riella M, Shlipak MG, Wang H, White CT, Winearls CG (2013) Kidney disease: improving global outcomes (KDIGO) CKD work group. KDIGO 2012 clinical practice guideline for the evaluation and management of chronic kidney disease. Kidney Int Suppl 3:1-150. https://doi.org/10.1038/kisup.2012.73

6. JSN, JRS and JCS Joint Working Group (2013) Guidelines on the use of iodinated contrast media in patients with kidney disease 2012: digest version. Circulation 77(7):1883-1914. https://doi. org/10.1253/circj.cj-66-0069

7. Yang JQ, Ran P, Chen JY, He YT, Li LW, Tan N, Li G, Sun S, Liu Y, Zhan JX, Zheng JY, Zhou YL (2014) Development of contrast-induced acute kidney injury after elective contrast media exposure in patients with type 2 diabetes mellitus: effect of albuminuria. PLoS ONE 9(9):e106454. https://doi.org/10.1371/journ al.pone.0106454

8. Mehran R, Aymong ED, Nikolsky E, Lasic Z, Iakovou I, Fahy M, Mintz GS, Lansky AJ, Moses JW, Stone GW, Leon MB, Dangas G (2004) A simple risk score for prediction of contrast-induced nephropathy after percutaneous coronary intervention: development and initial validation. J Am Coll Cardiol 44(7):1393-1399. https://doi.org/10.1016/j.jacc.2004.06.068

9. National Kidney Foundation (2002) K/DOQI clinical practice guidelines for chronic kidney disease: evaluation, classification, and stratification. Am J Kidney Dis 39(2 Suppl 1):S1-266

10. Levine GN, Bates ER, Blankenship JC, Bailey SR, Bittl JA, Cercek B, Chambers CE, Ellis SG, Guyton RA, Hollenberg SM, Khot UN, Lange RA, Mauri L, Mehran R, Moussa ID, Mukherjee D, Nallamothu BK, Ting HH (2011) 2011 ACCF/AHA/SCAI guideline for percutaneous coronary intervention: executive summary: a report of the American College of Cardiology Foundation/American Heart Association task force on practice guidelines and the society for cardiovascular angiography and interventions. Circulation 124(23):2574-2609. https://doi.org/10.1161/CIR.0b013e3182 $3 \mathrm{a} 5596$

11. Nash K, Hafeez A, Hou S (2002) Hospital-acquired renal insufficiency. Am J Kidney Dis 39(5):930-936. https://doi.org/10.1053/ ajkd.2002.32766

12. Maioli M, Toso A, Leoncini M, Gallopin M, Musilli N, Bellandi F (2012) Persistent renal damage after contrast-induced acute kidney injury: incidence, evolution, risk factors, and prognosis. Circulation 125(25):3099-3107. https://doi.org/10.1161/CIRCU LATIONAHA.111.085290

13. Wi J, Ko YG, Kim JS, Kim BK, Choi D, Ha JW, Hong MK, Jang Y (2011) Impact of contrast-induced acute kidney injury with transient or persistent renal dysfunction on long-term outcomes of patients with acute myocardial infarction undergoing percutaneous coronary intervention. Heart 97(21):1753-1757. https://doi. org/10.1136/hrt.2010.218677

14. Nemoto N, Iwasaki M, Nakanishi M, Araki T, Utsunomiya M, Hori M, Ikeda N, Makino K, Itaya H, Iijima R, Hara H, Takagi T, Joki N, Sugi K, Nakamura M (2014) Impact of continuous deterioration of kidney function 6 to 8 months after percutaneous coronary intervention for acute coronary syndrome. Am J 
Cardiol 113(10):1647-1651. https://doi.org/10.1016/j.amjca rd.2014.02.019

15. Marenzi G, Lauri G, Assanelli E, Campodonico J, De Metrio M, Marana I, Grazi M, Veglia F, Bartorelli AL (2004) Contrastinduced nephropathy in patients undergoing primary angioplasty for acute myocardial infarction. J Am Coll Cardiol 44(9):17801785. https://doi.org/10.1016/j.jacc.2004.07.043

16. Benzer M, Alpay H, Baykan O, Erdem A, Demir IH (2016) Serum NGAL, cystatin C and urinary NAG measurements for early diagnosis of contrast-induced nephropathy in children. Ren Fail 38(1):27-34. https://doi.org/10.3109/0886022X.2015.1106846

17. Newhouse JH, Kho D, Rao QA, Starren J (2008) Frequency of serum creatinine changes in the absence of iodinated contrast material: implications for studies of contrast nephrotoxicity. AJR Am J Roentgenol 191(2):376-382. https://doi.org/10.2214/ AJR.07.3280

18. Molnar AO, Parikh CR, Sint K, Coca SG, Koyner J, Patel UD, Butrymowicz I, Shlipak M, Garg AX (2012) Association of postoperative proteinuria with AKI after cardiac surgery among patients at high risk. Clin J Am Soc Nephrol 7(11):1749-1760. https://doi.org/10.2215/CJN.13421211

19. Meng $\mathrm{H}, \mathrm{Wu} \mathrm{P}$, Zhao Y, Xu Z, Wang ZM, Li C, Wang L, Yang Z (2016) Microalbuminuria in patients with preserved renal function as a risk factor for contrast-induced acute kidney injury following invasive coronary angiography. Eur J Radiol 85(6):1063-1067. https://doi.org/10.1016/j.ejrad.2016.03.010

20. Saito Y, Watanabe M, Aonuma K, Hirayama A, Tamaki N, Tsutsui H, Murohara T, Ogawa H, Akasaka T, Yoshimura M, Sato A, Takayama T, Sakakibara M, Suzuki S, Ishigami K, Onoue K (2015) Proteinuria and reduced estimated glomerular filtration rate are independent risk factors for contrast-induced nephropathy after cardiac catheterization. Circ J 79(7):1624-1630. https://doi. org/10.1253/circj.CJ-14-1345

21. Guo JK, Marlier A, Shi H, Shan A, Ardito TA, Du ZP, Kashgarian M, Krause DS, Biemesderfer D, Cantley LG (2012)
Increased tubular proliferation as an adaptive response to glomerular albuminuria. J Am Soc Nephrol 23(3):429-437. https:// doi.org/10.1681/ASN.2011040396

22. Khan S, Cabral PD, Schilling WP, Schmidt ZW, Uddin AN, Gingras A, Madhavan SM, Garvin JL, Schelling JR (2018) Kidney proximal tubule lipoapoptosis is regulated by fatty acid transporter-2 (FATP2). J Am Soc Nephrol 29(1):81-91. https://doi. org/10.1681/ASN.2017030314

23. Levey AS, Becker C, Inker LA (2015) Glomerular filtration rate and albuminuria for detection and staging of acute and chronic kidney disease in adults: a systematic review. JAMA 313(8):837846. https://doi.org/10.1001/jama.2015.0602

24. Kuusniemi AM, Lapatto R, Holmberg C, Karikoski R, Rapola J, Jalanko H (2005) Kidneys with heavy proteinuria show fibrosis, inflammation, and oxidative stress, but no tubular phenotypic change. Kidney Int 68(1):121-132. https://doi.org/10.111 1/j.1523-1755.2005.00386.x

25. Webster AC, Nagler EV, Morton RL, Masson P (2017) Chronic kidney disease. Lancet 389(10075):1238-1252. https://doi. org/10.1016/S0140-6736(16)32064-5

26. Donadelli R, Abbate M, Zanchi C, Corna D, Tomasoni S, Benigni A, Remuzzi G, Zoja C (2000) Protein traffic activates NF-kB gene signaling and promotes MCP-1-dependent interstitial inflammation. Am J Kidney Dis 36(6):1226-1241. https://doi.org/10.1053/ ajkd.2000.19838

27. Pisani A, Riccio E, Andreucci M, Faga T, Ashour M, Di Nuzzi A, Mancini A, Sabbatini M (2013) Role of reactive oxygen species in pathogenesis of radiocontrast-induced nephropathy. Biomed Res Int 2013:868321. https://doi.org/10.1155/2013/868321

Publisher's Note Springer Nature remains neutral with regard to jurisdictional claims in published maps and institutional affiliations. 